\title{
Ignore this heading. It will not influence your interpretation of this article ... or will it?
}

Michele van Eck

BCom LLM LLD

Lecturer, Department of Private Law, University of Johannesburg

\begin{abstract}
SUMMARY
The contractual drafting process has been plagued with the copy-and-paste phenomena in which clauses are often incorporated into an agreement on the strength that such a clause is considered standard or a boilerplate, with little consideration to the rationale for its potential interpretative value in a contract. A headings clause has fallen victim to this drafting practice. A headings clause is often used as an interpretative tool to address the manner in which headings would be interpreted within the context of a contract. Headings certainly have practical purposes and normally serves as a navigational tool, but may also have interpretational value on the substantive provisions of a contract. This paper considers four scenarios in which headings could impact the interpretation of a contract and the influence a headings clause may have in such scenarios. A headings clause could, for example, only require the interpreter to consider headings for convenience and thereby circumvent any other interpretative value of the heading, other than serving as a navigational tool. Headings clauses may also exclude the operation of headings from the interpretative processes altogether in which case the interpreter is directed to ignore the headings used in the contract. Although strictly speaking this would mean that headings cannot be used in the interpretation process at all, it seems likely that headings would still under the circumstances be used as navigational tools. On occasion headings may influence the interpretation of subclauses, or sub-clauses may be incorrectly drafted which headings may then clarify. Headings may also inaccurately reflect the content of the agreement or sub-clauses which may lead to the availability of iustus error to escape the contract. Headings clauses may be included in a contract in an attempt to circumvent such risks and create a safety net for drafting errors. It is apparent that a headings clause would have an impact on the interpretation of the contract and can hardly be considered as a standard provision within a contract.
\end{abstract}




\section{Introduction}

In the drafting of contracts, headings are used in various ways. Headings can be included in the interpretation of an agreement or could be used as a tool to navigate an agreement. A heading could refer to the heading or title of the agreement itself, which often describes the type of agreement, ${ }_{2}^{1}$ or it could refer to the headings used within the text of the agreement. $^{2}$

Generally, the purpose of headings are to guide and assist the reader to navigate the agreement. Headings have been described as organisational tools, ${ }^{3}$ rough indicators of the content of the subsections, ${ }^{4}$ abbreviations, ${ }^{5}$ and even preambles to those sections that follow the heading. ${ }^{6}$ Headings essentially help the reader to digest the content of the document, without which a lengthy agreement could become overwhelming.

Headings, in their assistance in digesting written discourse, have been recognised and encouraged in plain language drafting. The Companies Act 2008, Consumer Protection Act 2008, National Credit Act 2005, requires certain agreements (and other documents) to be drafted in plain language. ${ }^{7}$ It is worth noting that, although the Consumer Protection Act 2008 and the National Credit Act 2005 only applies to certain agreements, these Acts encourage the use of headings to achieve plain language in agreements. Headings are obviously also used in other agreements that do not fall within the scope of the Consumer Protection Act 2008 and the National Credit Act 2005.

Sometimes drafters attempt to remove the application of the headings in an agreement by including a headings clause. A headings clause can

1 The heading to the agreement can also be called the headnote or title. The description found in the heading is often used to describe the specific type of contract. The type of contract is, however, not determined by what the contract is called in its title but instead the type of contract is determined by the essentialia found in the agreement.

2 Headings can also be referred to as captions or titles.

3 The US case of McEwan v Mountain Land Support Corporation 116 P.3d 955 2005 UT App 240 961, the court describes headings in contracts to be “... more appropriately regarded as organizational tools than substantive contract provisions".

$4 \quad$ Rex $v$ Associated Trade Suppliers Ltd and Another 1945 AD 611616.

5 Sentinel Mining Industry Retirement Fund and Another $v$ Waz Props (Pty) Ltd and Another 2016 JOL 35527 (SCA) 7.

6 The Rex case 615, referencing Fletcher $v$ Birkenhead Corporation, describes a heading as a preamble, which implies that the heading has no substantive force but is useful in "explaining doubtful expressions in the body of a section". In other words, headings do not appear, in themselves, to create obligations. It does, however, like with a preamble of a contract, influence the interpretation of a contract by providing interpretative guidance to the provisions that follow.

7 S6bis(5) of the Companies Act 61 of 2008; s22bis(2)(d) of the Consumer Protection Act 68 of 2008; s64bis(2)(d) of the National Credit Act 34 of 2005. 
be as wide as stating that headings do not influence the interpretation of the agreement, or as narrow as stating that headings are only included in the agreement for convenience. Such headings clauses are often thought to be boilerplate or some standard provision normally included in agreements. ${ }^{8}$ The myth of standard clauses has unfortunately been perpetuated by the copy-and-paste phenomena found in contract drafting practice. Notwithstanding this, each clause must have a purpose and there must be a reason for the inclusion of the provision in the agreement. It is not good enough to include a provision in an agreement on the strength of the perception that such a provision is considered to be a standard clause.

In addition, a presumption exists in our law that every word included in an agreement has meaning and a purpose. ${ }^{9}$ If every word in an agreement has an attached meaning, then by implication such a word would influence the interpretation of an agreement. The same reasoning would apply to headings in agreements. Therefore, headings clauses could influence the interpretation of an agreement. Some agreements, however, exclude headings from the interpretation of an agreement. ${ }^{10}$ The exact reason for such exclusion may be to avoid errors or incomplete headings influencing the interpretation of the clauses bundled underneath the heading. ${ }^{11}$ Taking the presumption that every word contained in the agreement would influence the interpretation of the agreement as the starting point, it is not the norm to intentionally exclude headings from the interpretation of an agreement, as headings would have been included in the agreement for a reason. ${ }^{12}$

To understand the purpose and effect of headings in agreements, a closer inspection of the headings clause is necessary. Some headings clauses describe headings as being included in the agreement for convenience only, which implies that there may still be some scope for headings to be part of the interpretation of the agreement. ${ }^{13}$ The second

8 The term boilerplate is used to refer to standardised clauses in a contract. See: Anderson \& Warner in A-Z Guide to Boilerplate and Commercial Clauses (2012) 1; Stark in Negotiating and Drafting Boilerplate (2003) 9-10.

9 Cornelius in Principles of the Interpretation of Contracts in South Africa (2007) 122 .

10 For the purposes of this this article, these types of provisions will be referred to as headings clauses.

11 Bracher "Headings will be taken seriously" 2015 Financial Institutions Legal Snapshot http://www.financialinstitutionslegalsnapshot.com/2015/06/head ings-will-be-taken-seriously/ (accessed 2019-11-19), which notes due to the interpretational impact headings may have on a contract it is the reason "... why many contracts exclude the headings as part of the document".

12 Toedt "General provisions in contracts" 2012 Common Draft Annotated Compendium http://www.oncontracts.com/general-provisions/\#fn.51 (accessed 2015-09-13).

13 An example is found in Fosbrook \& Laing in The $A-Z$ of Contract Clauses (2014) I.343, "the headings in this Agreement are for convenience only [and] shall have no effect on the interpretation of the document", or I.349, "[h] $\mathrm{h}$ eadings, clauses and other parts are for reference only and are not to be construed as part of this Contract". 
type of headings clause excludes headings from the agreement altogether, or states that headings should be ignored. ${ }^{14}$ If the application of headings are removed from the agreement through headings clauses, then the agreements may achieve the same outcome by simply eliminating the use of headings from the document altogether.

This article considers the purpose of headings in an agreement and the use of headings clauses by examining four general examples, each setting out different scenarios in which headings and headings clauses could be used in an agreement.

\section{First example: headings are for convenience only $^{15}$}

In this example, the use of headings do not create ambiguity in an agreement, but a headings provision provides that headings should only be used for convenience. In this case, headings are not necessarily intended to be excluded in their entirety from an agreement and are still intended to be used as navigational tools within the document.

Take for instance a shareholders agreement, which typically includes a number of headings. Should the reader wish to find the provisions relating to, for example, voting rights, they would look for the relevant heading to guide them to the right section in the agreement. Headings, in this instance, have undoubtedly been used to aid the reader in digesting and navigating the agreement.

A presumption exists in our law that there are no superfluous or meaningless words included in an agreement. ${ }^{16}$ Starting from this basis, the use of a heading must have intended to mean something when it was included in the agreement. In this example, the headings are clearly intended to function as a navigational tool, but headings clauses also typically state that headings should not be used for interpretation or give substantive weight to the agreement. Therefore, the headings clause often intends to exclude the substantive application of headings, but at the same time intends to use headings in the traditional sense to navigate the document. It could be argued that merely having included the heading as part of the text, has already influenced the interpretation of

14 Fosbrook \& Laing I.341 sets out the following example: "[c]lause headings or titles do not form part of this contract and shall not affect its interpretation".

15 My gratitude is extended to Mr Angelo Christophorou for his valuable insights and providing this example to illustrate the practical functioning of a headings clause.

16 Cornelius 122 , every word in a contract has a purpose and there are no meaningless, superfluous or tautological words contained in a contract. On this basis, if a heading had been included in a contract, then the heading must serve a purpose and would then influence the interpretation of the contract to some extent. See also: Benz v SA Lead Works Ltd 19633 SA 797 (A). 
agreement. This line of reasoning seems artificial in that the headings clause has already directed how the headings should be used in the interpretation of the agreement. This first example, however, does highlight that headings could be included in an agreement to serve as a navigational tool in order to help readers traverse their way through an agreement.

\section{Second example: headings should be ignored $^{17}$}

A headings clause could also be an attempt to overcome errors or shortcomings found in the manner in which an agreement was drafted. Headings in these instances may cast doubt, or create some level of ambiguity, in the interpretation of sub-clauses. Take for example the ambiguity where a section heading is titled "warranties" and underneath the heading one of the sub-clauses states that the creditor will make payment of the fees into the debtor's bank account by electronic funds transfer. The heading refers to a warranty, but the sub-clause beneath it does not. If the heading is ignored then the creditor should make payment to the debtor by electronic funds transfer. If the heading is read together with the sub-clauses, then the heading may amplify the meaning of the sub-clause and could imply that the obligation is, in fact, a warranty. The heading would then expand and possibly change the original meaning of the sub-clause. To avoid these types of interpretative consequences, drafters often include a headings clause directing the interpreter to ignore the interpretational impact of the headings within the text. ${ }^{18}$ Excluding the interpretative application of the heading in this fashion could very well render headings in the agreement without purpose or function.

17 Fosbrook \& Laing I.341

18 A similar example is discussed in Adams "You might want to make your section headings non-random" 2012 http://www.adamsdrafting.com/youmight-want-to-make-your-section-headings-non-random/ (accessed 201911-19), which discusses the US case of Corbin Bernsen $v$ Innovative Legal Marketing. In this case the section heading was called "Indemnification" and read as follows: "VI. INDEMNIFICATION. Network will name Talent on its general liability insurance policy. Talent agrees to not commit any act or do anything which may tend to bring Talent into public disrepute, contempt, scandal or ridicule or which might tend to reflect unfavorably on the Network, their clients or on the Talent." It is clear from the content of the clause that there was no indemnification in the so-called morality clause. The argument that the clause contained some form of implied indemnification did not succeed in this case. 
If headings are to be ignored in their entirety then the interpreter may not take into account the headings at all when reading the agreement. ${ }^{19}$ It could then be argued to mean that headings cannot be used for convenience to navigate the agreement, as shown in the first example. ${ }^{20}$ If this was the intention of the headings clause, then the drafter could have achieved the same result by excluding headings from the agreement altogether.

The rules of interpretation notes that every word in the agreement has been included for a specific reason and purpose. ${ }^{21}$ After all, the interpretation of an agreement cannot be sliced, diced and compartmentalised. ${ }^{22}$ Instead, an agreement should be interpreted as a whole to ascertain the intention of the parties. As such, the headings clause in this example does not appear to have the effect of excluding headings from the agreement altogether, but the heading could still have the purpose of navigating the agreement.

It may also be suggested that the purposes of a headings clause is to clarify the ambiguity between headings and substantive provisions. If this was the case, then the same outcome could be achieved by adapting a conflict clause to state the substantive provisions of the sub-clauses would take preference over any conflict with the headings clause. ${ }^{23}$ The provisions found underneath a heading would most likely contain the intention of the parties. ${ }^{24}$ The headings and the provisions sub-clauses found underneath it should be read together, and insofar as they are inconsistent, the courts have indicated the substantive provision would take preference. ${ }^{25}$ Therefore, including an adapted conflicts clause adds little additional value to the existing position.

19 See for example the US case of Sunoco Inc $(R \& M) v$ Toledo Edison Co 129 Ohio St.3d 3972011 -Ohio-2720 413, where the headings clause functioned as a type of waiver in which the parties could not rely on the headings in interpreting the agreement. Also, in the US case of Home Gas Corporation $v$ Strafford Fuel Inc. and Edward C. Dupont. Jr. 130 N.H. 74 1984, the headings were ignored in the interpretation of the section because of the inclusion of a headings clause in the agreement.

20 See discussion in para 2.

21 Cornelius 122.

22 In the US case of Nicolas M Salgo Associates $v$ Continental Illinois Properties 532 F.Supp. 2791981 281, the court confirmed that a part of a contract cannot be interpreted in isolation but must be considered as a whole. This is similar to the South African approach to the interpretation of contracts.

23 This type of provision could read to say that any conflict between the heading and the substantive provisions underneath it, the substantive provisions would take preference.

24 The Sentinel Mining Industry Retirement Fund case 7.

25 The Sentinel Mining Industry Retirement Fund case 7, the court provides guidance to the interpretation of conflicts between the headings and subclauses by stating "[i]t seems to me common sense that where a heading conflicts with the body of the contract, it must be the body of the contract which prevails because the parties' intention is more likely to appear from the provisions they have spelt out than from an abbreviation they have 
This second example illustrates that the headings clause could be used to remove headings from influencing the substantive form to the agreement and may also exclude headings from the interpretation of the agreement altogether. This, however, does not appear to impact the navigational function of headings in an agreement.

\section{Third example: headings are used to avoid ambiguity $^{26}$}

Sometimes the incorrect use of headings creates ambiguity. It may be suggested that the inclusion of a headings clause is intended to avoid such ambiguity. This is not always necessarily the case. Ambiguity can also be created where a headings clause has been included in the agreement and sub-clauses either do not refer to heading, or makes an incorrect reference to the heading.

Take for example a clause that is titled "19. Liability". The first subclause, clause 19.1, speaks to the creditor being liable for any negligent actions in loading machines onto the debtor's vehicle. The second subclause, clause 19.2, speaks to the debtor being liable for any loss or damage to machines whilst such machines are in the debtor's custody. The third sub-clause, clause 19.3, reads: "Nothing in this clause shall imply that a party will be liable for indirect or special damages whatsoever." The heading does not, in itself, create ambiguity as it accurately captures the theme of the sub-clauses, being the allocation of liability between the contracting parties. The ambiguity is, however, introduced in the manner in which clause 19.3 is drafted. Without the heading "Liability", clause 19.3's use of the words, "this clause" is ambiguous, in that it is not clear whether "this clause" refers to clause 19.3 itself or to clause 19 as a whole. The inclusion of the heading potentially removes such ambiguity. ${ }^{27}$ The question that is derived from this scenario is whether a headings clause that instructs the reader to ignore headings could result in the heading "Liability" not be considered at all when interpreting clause 19.3. The author would argue that this line of reasoning creates a level of artificiality and unnecessary technicality in interpreting the agreement. Despite this textual ambiguity, it remains likely that the drafter intended clause 19.3 to refer to the heading "Liability".

This example illustrates that the heading itself did not create the ambiguity but rather that the manner in which the sub-clauses were drafted and the inclusion of a headings clause resulted in the textual

chosen to identify the effect of those provisions[,] ... but that where the heading and the detailed provisions can be read together, that should be done".

26 This example is adapted from a contract that the author reviewed.

27 Kilburn v Tuning Fork (Pty) Ltd 20156 SA 244 (SCA) 249, when the heading and the body of the agreement was read together the ambiguity that existed was resolved. 
ambiguity. Any references to the headings in the sub-clauses could, in itself, create ambiguity and even more so where headings clauses have been included in the agreement.

\section{Fourth example: headings highlighting the content of the agreement}

Headings could highlight the content or theme of sub-clauses within the agreement and thereby limit a party from arguing that a misunderstanding existed regarding the content of the agreement. The text of an agreement may, for example, be misleading, ${ }^{28}$ and could induce a person in signing the document. ${ }^{29}$ This may give rise to the argument of iustus error. This could include instances where the incorrect or incomplete use of headings ${ }^{30}$ creates an impression contrary to the provisions in the contract. Consequently, the contracting party would not have expected such provisions in a particular type of agreement. There are a number of factors that can influence whether the argument of iustus error would be successful and the use of headings can be one of these factors.

In Fourie $v$ Hansen, ${ }^{31}$ the manner in which the document was structured discouraged a person from reading it. ${ }^{32}$ The heading of the document did not bring to the signatory's attention the exemption provision contained in the document and the signatory was led to believe that the document was nothing more than a confirmation of receipt. The signatory, therefore, did not expect an exemption clause to be present in the agreement. ${ }^{33}$

Another example is where the heading to the agreement did not fully describe its content of the agreement. This was the case in Keens Group $v$ Lotter, ${ }^{34}$ where the contract was titled as "Confidential: Application for Credit Facilities", but the agreement contained a suretyship. This

28 Brink $v$ Humphries \& Jewel (Pty) Ltd 20052 All SA 343 (SCA) 345, a document can be found misleading in its terms, which would constitute a misrepresentation and could cause the signatory to rescind the contract where the misrepresentation was material.

29 Adams "Accentuating the positive in section headings" 2011 http:// www.adamsdrafting.com/accentuating-the-positive-in-section-headings/ (accessed 2019-11-19), states that section-headings, being a summary of the clause, could also be considered to be misleading if incorrectly described.

30 The Brink case 348-349.

31 Fourie $v$ Hansen 2000 JOL 5993 (W).

32 The Fourie case 14, the court stated that a different colour, underlining or having the clause in bigger font would bring the provision to the reader's attention.

33 The Fourie case 16.

34 Keens Group Co (Pty) Ltd v Lotter 19891 All SA 49 (C). 
amounted to the inclusion of an unusual term in the agreement and allowed for the successful argument of iustus error. ${ }^{35}$

Incorrect headings are not the only factor and cannot, in itself, be the sole feature that determines whether iustus error applies, as seen in Brink $v$ Humphries. ${ }^{36}$ In other instances, the courts have upheld the principle of caveat subscriptor, insisting that the reader should have read the agreement before signing it. ${ }^{37}$ The inclusion of correct headings could be used to reinforce the caveat subscriptor principle in such instances.

A number of factors would influence whether a party can successfully rely on the argument of iustus error, but the test ultimately rests on whether a reasonable man would find the text misleading. ${ }^{38}$ Take for instance Brink $v$ Humphries, ${ }^{39}$ in which some of these factors included: ${ }^{40}$ (i) whether the heading of the contract was misleading, ${ }^{41}$ (ii) whether the signatory had to sign twice in different capacities, (iii) the fact that some of the clauses had to be completed by the signatory's own hand, and (iv) the fact that the surety provision was in capital letters. ${ }^{42}$ In this instance, headings were not the only influencing factor, ${ }^{43}$ but headings could be an influencing factor where there is a duty placed on a party to bring to the signatories' attention certain provisions. ${ }^{44}$ A drafter could, in such circumstances, use other mechanisms to draw the signatory's attention to provisions, including different colour text, font size, capital letters, underlining or bolding text or even having the signatory initial next to the provision.

The converse may also be true in that sub-clauses, for example, have a wider meaning than the heading used to describe the clause, which could create a false impression to the contracting parties. Take for instance a clause titled "Assignment", which may not accurately reflect the sub-clauses that includes a prohibition against informal cession or a

35 The Keens Group case 56, the court favoured the use of a separate document so that the intention of the parties was clear.

36 The Brink case 348-349. See also: Roomer v Wedge Steel (Pty) Ltd 1997 JOL 1345 (W); Royal Canin South Africa (Pty) Ltd v Cooper 2009 JOL 22720 (SE).

37 Take for example Blue Chip Consultants (Pty) Ltd v Shamrock 2002 JOL 9307 (W) 13 in which the court found the form was not misleading because of the relationship of the parties.

38 The Brink case 348-349.

39 The Brink case 345.

40 The Brink case 348-349.

41 The fact that the credit application in this case did not make reference to the suretyship was misleading in itself.

42 In this case the effect of the capital letters was diluted by the preceding clauses being in capital letters as well.

43 For example, George v Fairmead 19583 All SA 1 (A), the words "I hereby agree" was an indicator that an agreement was being entered into irrespective of it being called a hotel register.

44 In Diners Club SA (Pty) Ltd v Livingstone 19954 All SA 334 (W), the typographical readability of the contract was poor, and the font was so small that a magnifier was necessary to read the text. 
pactum de non cedendo, which is not strictly the same legal concept as "assignment" set out in the section heading.

This final example illustrates another purpose of headings, being that headings highlight the content and substance of an agreement.

\section{Conclusion}

The use of headings can create ambiguity if headings do not accurately reflect the content of the sub-clauses. ${ }^{45}$ Similar pitfalls may exist where references are made to the heading in the sub-clauses. ${ }^{46}$ In addition, the use of headings in an agreement will either facilitate or prevent misunderstandings in relation to the content of the text. ${ }^{47}$

From the examples discussed, it is apparent that the so-called standard headings clauses are not so standard after all and that headings, in whichever form used, can become an interpretative risk in poor contractual drafting. ${ }^{48}$ Sometimes, it seems that a headings clause is an attempt to cast a safety net in an agreement to catch any drafting errors. It has, however, been illustrated that the drafting errors cannot always be hidden behind the protection of the headings clause. ${ }^{49}$

Headings may influence interpretation of an agreement and usually do not pose a problem if drafted correctly, in that the heading is concise, to the point and accurate. If a drafter wishes headings to be ignored, then headings could be avoided altogether from the agreement. By doing this, however, it could create difficulties in navigating the document, ${ }^{50}$ and the agreement would ultimately be a poorer document as a result.

There are, however, clear and practical reasons for using headings in agreements. Not only do headings serve the purpose of being a navigational tool, but they also highlight the content of the document to the parties, which could limit a party's ability to rely on misunderstandings in cases of iustus error.

There is no right or wrong way when drafting a contract, but there are often better ways of drafting. ${ }^{51}$ It is always advisable to draft correctly

45 See discussion in para 3.

46 See discussion in para 4.

47 See discussion in para 5.

48 Adams "A reminder regarding section-heading protocol" 2011 http:// www.adamsdrafting.com/a-reminder-regarding-section-heading-protocol/ (accessed 2019-11-19), echoes the statement that headings provisions are often used to overcome poor drafting by stating that: “... a provision regarding the effect of section headings can save you from the consequences of careless drafting".

49 See discussion in para 4.

50 See discussion in para 2.

51 A saying used by Prof SJ Cornelius in his lectures on the drafting and interpretation of contracts. 
and accurately. This will reduce the risk of having inaccurate headings which may have an interpretational influence on the substantive content of the contract. ${ }^{52}$ Whichever approach is taken, the inclusion of a headings clause cannot be said to be standard, and it ultimately rests on the drafter to consider whether it is appropriate to include or exclude a headings clause from an agreement.

52 Adams "A reminder regarding section-heading protocol" 2011, referring to the US case of Sunoco Inc (R\&M) $v$ Toledo Edison Co Adams points out that: "drafters should make sure any given provision is clear enough so that no one has to look to the heading for clues as to meaning" and that "drafters should make sure no section heading suggest a meaning that is broader or narrower than what's covered in the related section". 